CUBO A Mathematical Journal Vol.16, Noㅇ, (121-134). June 2014

\title{
Some Coupled Coincidence Point Theorems in Partially Ordered Uniform Spaces
}

\author{
Aris Aghanians, Kamal Fallahi, \\ Kourosh Nourouzi \\ Faculty of Mathematics, \\ K. N. Toosi University of Technology, \\ P.O. Box 16315-1618, Tehran, Iran. \\ nourouzi@kntu.ac.ir
}

\author{
Donal O'Regan \\ School of Mathematics, Statistics and Applied \\ Mathematics, \\ National University of Ireland, Galway, \\ University Road, Galway, Ireland.
}

\begin{abstract}
In this paper we investigate the existence of coupled coincidence points for some contractions in partially ordered separated uniform spaces under the mixed g-monotone property. We generalize a known result in partially ordered metric spaces to uniform spaces and give new types of contractions and results in partially ordered uniform spaces.
\end{abstract}

\section{RESUMEN}

En este artículo investigamos la existencia de puntos de coincidencia acoplados de algunas contracciones en espacios uniformes separados ordenados parcialmente bajo la propiedad g-monótona de mezcla. Generalizamos un resultado conocido en espacios métricos ordenados parcialmente a espacios uniformes y entregamos tipos nuevos de contracciones y resultados para espacios uniformes ordenados parcialmente.

Keywords and Phrases: Separated uniform space; Mixed g-monotone property; Coupled coincidence point.

2010 AMS Mathematics Subject Classification: 54H25, 54E15. 


\section{Introduction and Preliminaries}

In [3], Gnana Bhaskar and Lakshmikantham investigated coupled fixed points for mappings having the mixed monotone property in metric spaces endowed with a partial order and they applied their coupled fixed point results to periodic boundary value problems. Lakshmikantham and Ćirić [4] generalized the results in [3] by considering coupled coincidence points and mappings having the mixed g-monotone property. Using compatible mappings in partially ordered metric spaces, Choudhury and Kundu [2] extended the coupled fixed point results in [3].

In this paper, we aim to give a new generalization of a fixed point result in [3] to partially ordered uniform spaces. Also, some new results on coupled coincidence points are presented.

We first start by recalling some notions in uniform spaces. An in-depth discussion of uniformity can be found in $[6]$.

A sequence $\left\{x_{n}\right\}$ in a uniform space $(X, \mathcal{U})$ (briefly, $\left.X\right)$ is said to be convergent to a point $x \in X$, denoted by $x_{n} \rightarrow x$, if for each entourage $U \in \mathcal{U}$, there exists an $N>0$ such that $\left(x_{n}, x\right) \in U$ for all $n \geq N$ and Cauchy if for each entourage $U \in \mathcal{U}$, there exists an $N>0$ such that $\left(x_{m}, x_{n}\right) \in U$ for all $m, n \geq N$. The uniform space $X$ is called sequentially complete if each Cauchy sequence in $X$ is convergent to some point of $X$.

A uniformity $\mathcal{U}$ on a set $X$ is separating if the intersection of all entourages in $\mathcal{U}$ is equal to the diagonal $\{(x, x): x \in X\}$. In this case, $X$ is is called a separated uniform space.

For any pseudometric $\rho$ on $X$ and any $r>0$, we set

$$
V(\rho, r)=\{(x, y) \in X \times X: \rho(x, y)<r\} .
$$

Let $\mathcal{F}$ be a family of (uniformly continuous) pseudometrics on $X$ that generates the uniformity $\mathcal{U}$ (see [1], Theorem 2.1). Denote by $\mathcal{V}$, the family of all sets of the form

$$
\bigcap_{i=1}^{n} \mathrm{~V}\left(\rho_{i}, r_{i}\right)
$$

where, $n \geq 1$ and $\rho_{i} \in \mathcal{F}, r_{i}>0$ for each $i$. Then $\mathcal{V}$ is a base for the uniformity $\mathcal{U}$, and the elements of $\mathcal{V}$ are called the basic entourages of $X$. If

$$
V=\bigcap_{i=1}^{n} V\left(\rho_{i}, r_{i}\right) \in \mathcal{V},
$$

then

$$
\alpha V=\bigcap_{i=1}^{n} V\left(\rho_{i}, \alpha r_{i}\right) \in \mathcal{V}
$$

for each positive number $\alpha$.

Recall that for any two subsets $\mathrm{U}$ and $\mathrm{V}$ of $\mathrm{X} \times \mathrm{X}$, we denote by $\mathrm{U} \circ \mathrm{V}$ the set of all pairs $(x, z) \in X \times X$ for which $(x, y) \in V$ and $(y, z) \in U$ for some $y \in X$. We shall need the following lemma. For more details, the reader is referred to [1]. 
Lemma 1.1. [1] Let $\mathrm{X}$ be a uniform space.

i) If $\mathrm{V}$ is a basic entourage of $\mathrm{X}$ and $0<\alpha \leq \beta$, then $\alpha \mathrm{V} \subseteq \beta \mathrm{V}$.

ii) If $\rho$ is a pseudometric on $\mathrm{X}$ and $\alpha, \beta>0$, then

$$
(x, y) \in \alpha V\left(\rho, r_{1}\right) \circ \beta V\left(\rho, r_{2}\right) \quad \text { implies } \quad \rho(x, y)<\alpha r_{1}+\beta r_{2} .
$$

iii) For each $\mathrm{x}, \mathrm{y} \in \mathrm{X}$ and each basic entourage $\mathrm{V}$ of $\mathrm{X}$, there exists a positive number $\lambda$ such that $(x, y) \in \lambda V$.

iv) Each basic entourage $\mathrm{V}$ of $\mathrm{X}$ is of the form $\mathrm{V}(\rho, 1)$ for some pseudometric $\rho$ (the Minkowski's pseudometric of $\mathrm{V}$ ) on $\mathrm{X}$.

Definition 1. [4] Let $(X, \preceq)$ be a partially ordered set and let $F: X \times X \rightarrow X$ and $g: X \rightarrow X$ be two mappings.

i) The mapping $F$ is said to have the mixed $g$-monotone property if $F$ is $g$-nondecreasing and $\mathrm{g}$-nonincreasing in its first and second arguments, respectively, that is,

$$
g\left(x_{1}\right) \preceq g\left(x_{2}\right) \Longrightarrow F\left(x_{1}, y\right) \preceq F\left(x_{2}, y\right) \quad\left(x_{1}, x_{2} \in X\right),
$$

and

$$
g\left(y_{1}\right) \preceq g\left(y_{2}\right) \Longrightarrow F\left(x, y_{2}\right) \preceq F\left(x, y_{1}\right) \quad\left(y_{1}, y_{2} \in X\right)
$$

for all $x, y \in X$.

ii) An element $(x, y) \in X \times X$ is called a coupled coincidence point for $F$ and $g$ if

$$
F(x, y)=g(x) \quad \text { and } \quad F(y, x)=g(y) .
$$

iii) The mappings $F$ and $g$ are called commutative if

$$
F(g(x), g(y))=g(F(x, y)) \quad(x, y \in X) .
$$

Setting $\mathrm{g}=\mathrm{I}_{\mathrm{X}}$ (the identity mapping of $\mathrm{X}$ ) in Definition 1 , we get the concepts of the mixed monotone property and coupled fixed point defined in [3].

\section{Main Results}

Throughout this section, we suppose that the nonempty set $X$ is equipped with a separating uniformity $\mathcal{U}$ and a partial order $\preceq$ unless otherwise stated. Also, we consider a partial order $\sqsubseteq$ on $\mathrm{X} \times \mathrm{X}$ defined by

$$
\left(x_{1}, y_{1}\right) \sqsubseteq\left(x_{2}, y_{2}\right) \Longleftrightarrow x_{1} \preceq x_{2} \quad \text { and } \quad y_{2} \preceq y_{1}
$$


By two comparable elements $(x, y)$ and $(u, v)$ of $X \times X$, we mean either $(x, y) \sqsubseteq(u, v)$ or $(u, v) \sqsubseteq$ $(x, y)$. Furthermore, we assume that $\mathcal{F}$ is a family of (uniformly continuous) pseudometrics on $X$ that generates the uniformity $\mathcal{U}$. We denote by $\mathcal{V}$, the family of all sets of the form $\bigcap_{i=1}^{n} V\left(\rho_{i}, r_{i}\right)$ in which for each $i, \rho_{i} \in \mathcal{F}, r_{i}>0$ and $n \geq 1$.

We have the following lemma:

Lemma 2.1. The Minkowski's pseudometric $\rho$ of a basic entourage $\mathrm{V}$ is jointly continuous, i.e., $x_{n} \rightarrow x$ and $y_{n} \rightarrow y$ imply $\rho\left(x_{n}, y_{n}\right) \rightarrow \rho(x, y)$.

Proof. Let $\varepsilon>0$ be given. Then there exists an $\mathrm{N}>0$ such that

$$
\left(x_{n}, x\right) \in \frac{\varepsilon}{2} V \quad \text { and } \quad\left(y_{n}, y\right) \in \frac{\varepsilon}{2} V \quad(n \geq N) .
$$

On the other hand, for each $n \geq 1$,

$$
\rho(x, y) \leq \rho\left(x, x_{n}\right)+\rho\left(x_{n}, y_{n}\right)+\rho\left(y_{n}, y\right) .
$$

Substituting $x$ and $y$ with $x_{n}$ and $y_{n}$ in (2.1), respectively, and combining the obtained inequalities yield

$$
\left|\rho\left(x_{n}, y_{n}\right)-\rho(x, y)\right| \leq \rho\left(x_{n}, x\right)+\rho\left(y_{n}, y\right)
$$

Hence, for $n \geq N$,

$$
\left|\rho\left(x_{n}, y_{n}\right)-\rho(x, y)\right|<\frac{\varepsilon}{2}+\frac{\varepsilon}{2}=\varepsilon
$$

Thus, $\rho\left(x_{n}, y_{n}\right) \rightarrow \rho(x, y)$.

To present our results, we need the following concept:

Definition 2. A mapping $g: X \rightarrow X$ is called sequentially continuous on $X$ if for each $x \in X$ and each sequence $\left\{x_{n}\right\}$ in $X$ converging to $X$, we have $g\left(x_{n}\right) \rightarrow g(x)$. Similarly, a mapping $F: X \times X \rightarrow X$ is called sequentially continuous on $X$ if $x_{n} \rightarrow x$ and $y_{n} \rightarrow y$ imply $F\left(x_{n}, y_{n}\right) \rightarrow F(x, y)$.

Definition 3. A partially ordered uniform space $X$ is called upper (lower) regular if for each nondecreasing (nonincreasing) sequence $\left\{x_{n}\right\}$ in $X$ converging to $x$, one has $x_{n} \preceq x\left(x \preceq x_{n}\right)$ for all $n \geq 1$.

Hereafter, by a pair $(F, g)$ we mean mappings $F: X \times X \rightarrow X$ and $g: X \rightarrow X$ such that $F$ has the mixed $g$-monotone property, the range of $g$ contains the range of $F$ and $F(X \times X)$ or $g(X)$ is a sequentially complete uniform subspace of $X$ unless otherwise stated.

We present some examples of such pairs.

Example 1. Consider $X=[0,+\infty)$ with the uniformity induced from the usual metric and define a partial order $\preceq$ by

$$
x \preceq y \Longleftrightarrow(x=y \quad \text { or } \quad x, y \in[0,1] \text { with } x \leq y) .
$$


Define $F: X \times X \rightarrow X$ and $g: X \rightarrow X$ by

$$
F(x, y)=\left\{\begin{array}{cc}
\frac{x^{2}-y^{2}}{3} & y \preceq x \\
0 & \text { otherwise }
\end{array} \quad \text { and } g(x)=x^{2}\right.
$$

for all $x, y \in X$. Then it is seen that the range of $g$ contains the range of $F$ since $g$ is surjective on $X$, and because $g\left(x_{1}\right) \preceq g\left(x_{2}\right)$ implies $x_{1} \preceq x_{2}$, it follows that $F$ has the mixed $g$-monotone property.

Example 2. Let $X=\{1,2,3\}$ and $\mathcal{U}$ be the discrete uniformity on $X$, that is, $\mathcal{U}=\mathcal{P}(X \times X)$ and note that each uniform subspace of $X$ is sequentially complete. Consider the partial order

$$
\preceq=\{(1,1),(2,2),(3,3),(1,2)\}
$$

on $\mathrm{X}$ and define $\mathrm{F}$ and $\mathrm{g}$ by

$$
\begin{aligned}
F=\{ & ((1,1), 1),((1,2), 3),((1,3), 1),((2,1), 2),((2,2), 3),((2,3), 1), \\
& ((3,1), 2),((3,2), 3),((3,3), 2)\},
\end{aligned}
$$

and $g=\{(1,1),(2,3),(3,2)\}$. Observe that $F(X \times X) \subseteq g(X)$; furthermore, $g\left(x_{1}\right) \preceq g\left(x_{2}\right)$ implies either $x_{1}=x_{2}$ or $x_{1}=1$ and $x_{2}=3$, and since

$$
\mathrm{F}(1, y) \preceq F(3, y) \quad \text { and } \quad F(x, 3) \preceq F(x, 1)
$$

for all $x, y \in X$, it follows that $F$ has the mixed $g$-monotone property. Here, $(1,1),(1,3),(3,1)$ and $(3,3)$ are the coupled coincidence points for $F$ and $g$.

Example 3. Let $X$ be a sequentially complete real topological vector space and $C$ a pointed cone in $X$, that is, $C \cap(-C)=\{0\}$. It is well-known that the topology of a topological vector space can be derived by a unique uniformity, i.e., every topological vector space is "uniformizable" in a unique way (for the details, see [5]). Consider $X$ with this uniformity and partial order $\preceq$ on $X$ induced by $\mathrm{C}$ as

$$
x \preceq y \Longleftrightarrow y-x \in C .
$$

Define mappings $\mathrm{F}: \mathrm{X} \times \mathrm{X} \rightarrow \mathrm{X}$ and $\mathrm{g}: \mathrm{X} \rightarrow \mathrm{X}$ by

$$
F(x, y)=x-y, \quad \text { and } g(x)=\left\{\begin{array}{cc}
x & x \in C \\
2 x & x \notin C
\end{array}\right.
$$

for all $x, y \in X$. Then using the properties of a cone, it is easy to check that $g$ is surjective on $X$. To see that $F$ has the mixed $g$-monotone property, note that $g\left(x_{1}\right) \preceq g\left(x_{2}\right)$ implies $x_{1} \preceq x_{2}$. Therefore, if $g\left(x_{1}\right) \preceq g\left(x_{2}\right)$, then

$$
F\left(x_{1}, y\right)=x_{1}-y \preceq x_{2}-y=F\left(x_{2}, y\right) \quad(y \in X) .
$$

Similarly, from $g\left(y_{1}\right) \preceq g\left(y_{2}\right)$ we get $F\left(x, y_{2}\right) \preceq F\left(x, y_{1}\right)$ for all $x \in X$. In this example, the coupled coincidence points for $\mathrm{F}$ and $\mathrm{g}$ are $(0,0)$ and all the pairs $(x,-x)$ with $x,-x \notin \mathrm{C}$. 
Theorem 2.1. Suppose that the pair $(\mathrm{F}, \mathrm{g})$ satisfies the following conditions:

i) there exist $\alpha, \beta>0$ with $\alpha+\beta<1$ such that

$$
(\mathrm{F}(\mathrm{x}, \mathrm{y}), \mathrm{F}(\mathrm{u}, v)) \in \alpha \mathrm{V}_{1} \circ \beta \mathrm{V}_{2}
$$

if $\mathrm{V}_{1}, \mathrm{~V}_{2} \in \mathcal{V},(\mathrm{g}(\mathrm{x}), \mathrm{g}(\mathrm{u})) \in \mathrm{V}_{1},(\mathrm{~g}(\mathrm{y}), \mathrm{g}(\mathrm{v})) \in \mathrm{V}_{2}$, and the pairs $(\mathrm{g}(\mathrm{x}), \mathrm{g}(\mathrm{y}))$ and $(\mathrm{g}(\mathrm{u}), \mathrm{g}(\mathrm{v}))$ are comparable, where $\mathrm{x}, \mathrm{y}, \mathrm{u}, \boldsymbol{v} \in \mathrm{X}$;

ii) there exist $\mathrm{x}_{0}, \mathrm{y}_{0} \in \mathrm{X}$ such that $\mathrm{g}\left(\mathrm{x}_{0}\right) \preceq \mathrm{F}\left(\mathrm{x}_{0}, \mathrm{y}_{0}\right)$ and $\mathrm{F}\left(\mathrm{y}_{0}, \mathrm{x}_{0}\right) \preceq \mathrm{g}\left(\mathrm{y}_{0}\right)$.

Then $\mathrm{F}$ and $\mathrm{g}$ have a coupled coincidence point if one of the following statements holds:

$(*) \mathrm{F}$ and $\mathrm{g}$ are commutative and sequentially continuous on $\mathrm{X}$;

$(* *) \mathrm{g}(\mathrm{X})$ is upper and lower regular.

Proof. Since $F(X \times X) \subseteq g(X)$, there exist $x_{1}, y_{1} \in X$ such that $g\left(x_{1}\right)=F\left(x_{0}, y_{0}\right)$ and $g\left(y_{1}\right)=$ $F\left(y_{0}, x_{0}\right)$. We can also choose $x_{2}, y_{2} \in X$ such that $g\left(x_{2}\right)=F\left(x_{1}, y_{1}\right)$ and $g\left(y_{2}\right)=F\left(y_{1}, x_{1}\right)$. Continuing this process, we get sequences $\left\{x_{n}\right\}$ and $\left\{y_{n}\right\}$ in $X$ such that

$$
g\left(x_{n+1}\right)=F\left(x_{n}, y_{n}\right) \text { and } g\left(y_{n+1}\right)=F\left(y_{n}, x_{n}\right) \quad(n \geq 0) .
$$

By induction, we now see that $\left\{\boldsymbol{g}\left(\boldsymbol{x}_{\mathfrak{n}}\right)\right\}$ and $\left\{\boldsymbol{g}\left(\mathrm{y}_{\mathbf{n}}\right)\right\}$ are nondecreasing and nonincreasing sequences in $g(X)$, respectively. In fact, $g\left(x_{0}\right) \preceq F\left(x_{0}, y_{0}\right)=g\left(x_{1}\right)$ and $g\left(y_{1}\right) \preceq g\left(y_{0}\right)$. If $g\left(x_{n-1}\right) \preceq g\left(x_{n}\right)$ and $g\left(y_{n}\right) \preceq g\left(y_{n-1}\right)$ for $n \geq 1$, since $F$ has the mixed $g$-monotone property, then

$$
g\left(x_{n}\right)=F\left(x_{n-1}, y_{n-1}\right) \preceq F\left(x_{n}, y_{n-1}\right) \preceq F\left(x_{n}, y_{n}\right)=g\left(x_{n+1}\right) .
$$

Similarly, $g\left(y_{n+1}\right) \preceq g\left(y_{n}\right)$.

Now, let $\mathrm{V} \in \mathcal{V}$ and suppose that $\rho$ is the Minkowski's pseudometric of $\mathrm{V}$. For given comparable elements $(g(x), g(y))$ and $(g(u), g(v))$ of $X \times X$, where $x, y, u, v \in X$, write $r_{1}=\rho(g(x), g(u))$ and $r_{2}=\rho(g(y), g(v))$ and take $\varepsilon>0$. Then

$$
(g(x), g(u)) \in\left(r_{1}+\varepsilon\right) V \quad \text { and }(g(y), g(v)) \in\left(r_{2}+\varepsilon\right) V,
$$

and, therefore, by (2.2), we have

$$
(F(x, y), F(u, v)) \in \alpha\left(r_{1}+\varepsilon\right) V \circ \beta\left(r_{2}+\varepsilon\right) V .
$$

From Lemma 1.1 we have

$$
\rho(F(x, y), F(u, v))<\alpha\left(r_{1}+\varepsilon\right)+\beta\left(r_{2}+\varepsilon\right)=\alpha r_{1}+\beta r_{2}+(\alpha+\beta) \varepsilon .
$$

Since $\varepsilon>0$ was arbitrary, it follows that

$$
\rho(F(x, y), F(u, v)) \leq \alpha \rho(g(x), g(u))+\beta \rho(g(y), g(v)) .
$$


Next, by Lemma 1.1, let $\lambda>0$ be such that

$$
\left(g\left(x_{1}\right), g\left(x_{0}\right)\right),\left(g\left(y_{1}\right), g\left(y_{0}\right)\right) \in \lambda V .
$$

Because $\left(g\left(x_{n}\right), g\left(y_{n}\right)\right)$ and $\left(g\left(x_{n-1}\right), g\left(y_{n-1}\right)\right)$ are comparable, by $(2.3)$, we have

$$
\begin{aligned}
\rho\left(g\left(x_{n+1}\right), g\left(x_{n}\right)\right) & =\rho\left(F\left(x_{n}, y_{n}\right), F\left(x_{n-1}, y_{n-1}\right)\right) \\
& \leq \alpha \rho\left(g\left(x_{n}\right), g\left(x_{n-1}\right)\right)+\beta \rho\left(g\left(y_{n}\right), g\left(y_{n-1}\right)\right),
\end{aligned}
$$

and similarly,

$$
\begin{aligned}
\rho\left(g\left(y_{n+1}\right), g\left(y_{n}\right)\right) & =\rho\left(F\left(y_{n}, x_{n}\right), F\left(y_{n-1}, x_{n-1}\right)\right) \\
& \leq \alpha \rho\left(g\left(y_{n}\right), g\left(y_{n-1}\right)\right)+\beta \rho\left(g\left(x_{n}\right), g\left(x_{n-1}\right)\right) .
\end{aligned}
$$

Therefore, setting

$$
\rho_{n}=\rho\left(g\left(x_{n+1}\right), g\left(x_{n}\right)\right)+\rho\left(g\left(y_{n+1}\right), g\left(y_{n}\right)\right) \quad n=0,1, \ldots,
$$

from (2.4) and (2.5) we obtain

$$
\begin{aligned}
\rho_{n} & =\rho\left(g\left(x_{n+1}\right), g\left(x_{n}\right)\right)+\rho\left(g\left(y_{n+1}\right), g\left(y_{n}\right)\right) \\
& \leq(\alpha+\beta)\left(\rho\left(g\left(x_{n}\right), g\left(x_{n-1}\right)\right)+\rho\left(g\left(y_{n}\right), g\left(y_{n-1}\right)\right)\right) \\
& =\delta \rho_{n-1},
\end{aligned}
$$

where $\delta=\alpha+\beta<1$. Thus, by induction, the inequality $\rho_{n} \leq \delta^{n} \rho_{0}$ holds for all $n \geq 0$. Hence, for sufficiently large $m$ and $n$ with $m>n$, we have

$$
\begin{aligned}
\rho\left(g\left(x_{m}\right), g\left(x_{n}\right)\right)+\rho\left(g\left(y_{m}\right), g\left(y_{n}\right)\right) & \leq \sum_{k=n+1}^{m}\left[\rho\left(g\left(x_{k}\right), g\left(x_{k-1}\right)\right)+\rho\left(g\left(y_{k}\right), g\left(y_{k-1}\right)\right)\right] \\
& =\rho_{m-1}+\cdots+\rho_{n} \\
& \leq\left(\delta^{m-1}+\cdots+\delta^{n}\right) \rho_{0} \\
& <\frac{\delta^{n}}{1-\delta} 2 \lambda<1,
\end{aligned}
$$

that is,

$$
\left(g\left(x_{m}\right), g\left(x_{n}\right)\right),\left(g\left(y_{m}\right), g\left(y_{n}\right)\right) \in V .
$$

Consequently, $\left\{g\left(x_{n}\right)\right\}$ and $\left\{g\left(y_{n}\right)\right\}$ are Cauchy sequences in $g(X)$, and so there exist $x, y \in X$ such that $g\left(x_{n}\right) \rightarrow g(x)$ and $g\left(y_{n}\right) \rightarrow g(y)$.

To see the existence of a coupled coincidence point for $\mathrm{F}$ and $\mathrm{g}$, suppose first that $(*)$ holds. Since $X$ is separated,

$$
g^{2}\left(x_{n+1}\right) \rightarrow g^{2}(x)
$$

with

$$
g^{2}\left(x_{n+1}\right)=g\left(F\left(x_{n}, y_{n}\right)\right)=F\left(g\left(x_{n}\right), g\left(y_{n}\right)\right) \rightarrow F(g(x), g(y))
$$


implies that $g^{2}(x)=F(g(x), g(y))$. Similarly, $g^{2}(y)=F(g(y), g(x))$, that is, $(g(x), g(y))$ is a coupled coincidence point for $\mathrm{F}$ and $\mathrm{g}$. On the other hand, if $(* *)$ holds, then

$$
g\left(x_{n}\right) \preceq g(x) \quad \text { and } \quad g(y) \preceq g\left(y_{n}\right),
$$

for all $n \geq 0$. Thus, $(g(x), g(y))$ is comparable to each $\left(g\left(x_{n}\right), g\left(y_{n}\right)\right)$. If $V \in \mathcal{V}$ and $\rho$ is the Minkowski's pseudometric of $\boldsymbol{V}$, then by (2.3) and Lemma 2.1, for sufficiently large $\mathfrak{n}$ we have

$$
\begin{aligned}
\rho(F(x, y), g(x)) & \leq \rho\left(F(x, y), g\left(x_{n+1}\right)\right)+\rho\left(g\left(x_{n+1}\right), g(x)\right) \\
& =\rho\left(F(x, y), F\left(x_{n}, y_{n}\right)\right)+\rho\left(g\left(x_{n+1}\right), g(x)\right) \\
& \leq \alpha \rho\left(g(x), g\left(x_{n}\right)\right)+\beta \rho\left(g(y), g\left(y_{n}\right)\right)+\rho\left(g\left(x_{n+1}\right), g(x)\right)<1,
\end{aligned}
$$

that is, $(F(x, y), g(x)) \in V$. Since $V$ is arbitrary and $X$ is separated, we get $F(x, y)=g(x)$. Similarly, $F(y, x)=g(y)$ and so, in this case, $(x, y)$ is a coupled coincidence point for $F$ and $g$.

Example 4. Let $X$ be a nonzero real vector space and $C$ be a pointed cone in $X$. Consider two arbitrary complete norms $\|\cdot\|_{1}$ and $\|\cdot\|_{2}$ on $X$ and define

$$
\rho_{1}\left(\left(x_{1}, x_{2}\right),\left(y_{1}, y_{2}\right)\right)=\left\|x_{1}-y_{1}\right\|_{1}
$$

and

$$
\rho_{2}\left(\left(x_{1}, x_{2}\right),\left(y_{1}, y_{2}\right)\right)=\left\|x_{2}-y_{2}\right\|_{2}
$$

for all $\left(x_{1}, x_{2}\right),\left(y_{1}, y_{2}\right) \in X^{2}=X \times X$. It is easy to verify that the uniformity $\mathcal{U}$ on $X^{2}$ generated by the two pseudometrics $\rho_{1}$ and $\rho_{2}$ is separating and sequentially complete. Define a partial order $\preceq$ on $X^{2}$ by

$$
\left(x_{1}, x_{2}\right) \preceq\left(y_{1}, y_{2}\right) \Longleftrightarrow y_{1}-x_{1}, x_{2}-y_{2} \in C \quad\left(\left(x_{1}, x_{2}\right),\left(y_{1}, y_{2}\right) \in X^{2}\right) .
$$

Since the family $\mathcal{F}=\left\{\rho_{1}, \rho_{2}\right\}$, which generates the uniformity $\mathcal{U}$ has finitely many elements, it follows that two mappings $F: X^{2} \times X^{2} \rightarrow X^{2}$ and $g: X^{2} \rightarrow X^{2}$ defined by

$$
F\left(\left(x_{1}, x_{2}\right),\left(y_{1}, y_{2}\right)\right)=\left(\frac{1}{3}\left(x_{1}-y_{1}\right), \frac{1}{4}\left(x_{2}-y_{2}\right)\right)
$$

and

$$
g\left(\left(x_{1}, x_{2}\right)\right)=\left(3 x_{1}, 2 x_{2}\right)
$$

for all $\left(x_{1}, x_{2}\right),\left(y_{1}, y_{2}\right) \in X^{2}$ satisfy (2.2) since they satisfy the contractive condition

$$
\begin{aligned}
\rho_{i}\left(F\left(\left(x_{1}, x_{2}\right),\left(y_{1}, y_{2}\right)\right), F\left(\left(u_{1}, u_{2}\right),\left(v_{1}, v_{2}\right)\right)\right) \leq & \frac{1}{4} \rho_{i}\left(g\left(\left(x_{1}, x_{2}\right)\right), g\left(\left(u_{1}, u_{2}\right)\right)\right) \\
& +\frac{1}{4} \rho_{i}\left(g\left(\left(y_{1}, y_{2}\right)\right), g\left(\left(v_{1}, v_{2}\right)\right)\right)
\end{aligned}
$$

for all $\left(x_{1}, x_{2}\right),\left(y_{1}, y_{2}\right),\left(u_{1}, u_{2}\right),\left(v_{1}, v_{2}\right) \in X^{2}$ such that the pairs $\left(g\left(\left(x_{1}, x_{2}\right)\right), g\left(\left(y_{1}, y_{2}\right)\right)\right)$ and $\left(\mathrm{g}\left(\left(\mathrm{u}_{1}, \mathrm{u}_{2}\right)\right), \mathrm{g}\left(\left(v_{1}, v_{2}\right)\right)\right)$ are comparable, and $\mathfrak{i}=1,2$. Moreover, $\mathrm{F}$ and $\mathrm{g}$ commute and are 
sequentially continuous on $X^{2}$, the mapping $F$ has the mixed g-monotone property and $F\left(X^{2} \times X^{2}\right) \subseteq$ $g\left(X^{2}\right)=X^{2}$. Therefore, setting $x_{0}=\left(-2 x^{*}, x^{*}\right)$ and $y_{0}=\left(x^{*},-2 x^{*}\right)$ where $x^{*} \in C$, we see that the hypotheses of Theorem 2.1 are fulfilled and hence $F$ and $g$ have a coupled coincidence point, namely $(0,0)$.

Setting $\mathrm{g}=\mathrm{I}_{\mathrm{X}}$ in Theorem 2.1, the following generalization of the Gnana Bhaskar and Lakshmikantham's result [3] to partially ordered uniform spaces is obtained.

Corolary 1. Suppose that $\mathrm{X}$ is sequentially complete and a mapping $\mathrm{F}: \mathrm{X} \times \mathrm{X} \rightarrow \mathrm{X}$ satisfies the following conditions:

i) F has the mixed monotone property;

ii) there exist $\alpha, \beta>0$ with $\alpha+\beta<1$ such that

$$
(\mathrm{F}(\mathrm{x}, \mathrm{y}), \mathrm{F}(\mathrm{u}, v)) \in \alpha \mathrm{V}_{1} \circ \beta \mathrm{V}_{2}
$$

if $\mathrm{V}_{1}, \mathrm{~V}_{2} \in \mathcal{V},(\mathrm{x}, \mathrm{u}) \in \mathrm{V}_{1},(\mathrm{y}, v) \in \mathrm{V}_{2}$, and the pairs $(\mathrm{x}, \mathrm{y})$ and $(\mathrm{u}, \boldsymbol{v})$ are comparable, where $x, y, u, v \in X$

iii) there exist $\mathrm{x}_{0}, \mathrm{y}_{0} \in \mathrm{X}$ such that $\mathrm{x}_{0} \preceq \mathrm{F}\left(\mathrm{x}_{0}, \mathrm{y}_{0}\right)$ and $\mathrm{F}\left(\mathrm{y}_{0}, \mathrm{x}_{0}\right) \preceq \mathrm{y}_{0}$.

Then $\mathrm{F}$ has a coupled fixed point if one of the following statements holds:

a) $\mathrm{F}$ is sequentially continuous on $\mathrm{X}$;

b) $\mathrm{X}$ is upper and lower regular.

Remark 1. In addition to the hypotheses of Theorem 2.1, suppose that $g\left(x_{0}\right) \preceq g\left(y_{0}\right)$. Suppose further that $x$ and $y$ are as in the proof of Theorem 2.1. Then $g(x)=g(y)$. To see this, we first show that $g\left(x_{n}\right) \preceq g\left(y_{n}\right)$ for all $n \geq 0$. If $g\left(x_{n}\right) \preceq g\left(y_{n}\right)$ for $n \geq 1$, since $F$ has the mixed g-monotone property, it follows that

$$
g\left(x_{n+1}\right)=F\left(x_{n}, y_{n}\right) \preceq F\left(y_{n}, y_{n}\right) \preceq F\left(y_{n}, x_{n}\right)=g\left(y_{n+1}\right) .
$$

Thus, by induction, $g\left(x_{n}\right) \preceq g\left(y_{n}\right)$ for all $n \geq 0$.

Now, let $V \in \mathcal{V}$ and $\rho$ be the Minkowski's pseudometric of $V$. Since $\left(g\left(x_{n}\right), g\left(y_{n}\right)\right)$ and $\left(g\left(y_{n}\right), g\left(x_{n}\right)\right)$ are comparable, by $(2.3)$, we have

$$
\begin{aligned}
\rho(g(x), g(y)) \leq & \rho\left(g(x), g\left(x_{n+1}\right)\right)+\rho\left(g\left(x_{n+1}\right), g\left(y_{n+1}\right)\right)+\rho\left(g\left(y_{n+1}\right), g(y)\right) \\
= & \rho\left(g(x), g\left(x_{n+1}\right)\right)+\rho\left(F\left(x_{n}, y_{n}\right), F\left(y_{n}, x_{n}\right)\right)+\rho\left(g\left(y_{n+1}\right), g(y)\right) \\
\leq & \rho\left(g(x), g\left(x_{n+1}\right)\right)+\alpha \rho\left(g\left(x_{n}\right), g\left(y_{n}\right)\right) \\
& +\beta \rho\left(g\left(y_{n}\right), g\left(x_{n}\right)\right)+\rho\left(g\left(y_{n+1}\right), g(y)\right)
\end{aligned}
$$




$$
\begin{aligned}
= & \rho\left(g(x), g\left(x_{n+1}\right)\right)+\delta \rho\left(g\left(x_{n}\right), g\left(y_{n}\right)\right)+\rho\left(g\left(y_{n+1}\right), g(y)\right) \\
\leq & \rho\left(g(x), g\left(x_{n+1}\right)\right)+\delta \rho\left(g\left(x_{n}\right), g(x)\right)+\delta \rho(g(x), g(y)) \\
& +\delta \rho\left(g(y), g\left(y_{n}\right)\right)+\rho\left(g\left(y_{n+1}\right), g(y)\right),
\end{aligned}
$$

where $\delta=\alpha+\beta<1$. Hence, the joint continuity of the Minkowski's pseudometrics yields

$$
\begin{aligned}
\rho(g(x), g(y)) \leq & \frac{1}{1-\delta} \rho\left(g(x), g\left(x_{n+1}\right)\right)+\frac{\delta}{1-\delta} \rho\left(g\left(x_{n}\right), g(x)\right) \\
& +\frac{\delta}{1-\delta} \rho\left(g(y), g\left(y_{n}\right)\right)+\frac{1}{1-\delta} \rho\left(g\left(y_{n+1}\right), g(y)\right)<1,
\end{aligned}
$$

for sufficiently large $n$, that is, $(g(x), g(y)) \in V$. Since $V$ is arbitrary and $X$ is separated, we get $g(x)=g(y)$. In particular, if $g$ is injective, then $F(x, x)=g(x)$.

We next present two coupled coincidence point theorems for two different types of contractions in partially ordered uniform spaces.

Theorem 2.2. Suppose that a pair (F,g) satisfies the following conditions:

i) there exist positive numbers $\alpha$ and $\beta$ with $\alpha+\beta<1$ such that for all $\mathrm{V}_{1}, \mathrm{~V}_{2} \in \mathcal{V}$, if $(\mathrm{F}(\mathrm{x}, \mathrm{y}), \mathrm{g}(\mathrm{x})) \in$ $\mathrm{V}_{1},(\mathrm{~F}(\mathrm{u}, v), \mathrm{g}(\mathrm{u})) \in \mathrm{V}_{2}$, and $(\mathrm{g}(\mathrm{x}), \mathrm{g}(\mathrm{y}))$ and $(\mathrm{g}(\mathrm{u}), \mathrm{g}(v))$ are comparable, then

$$
(\mathrm{F}(\mathrm{x}, \mathrm{y}), \mathrm{F}(\mathrm{u}, v)) \in \alpha \mathrm{V}_{1} \circ \beta \mathrm{V}_{2} \text {, }
$$

where $\mathrm{x}, \mathrm{y}, \mathrm{u}, \boldsymbol{v} \in \mathrm{X}$;

ii) there exist $\mathrm{x}_{0}, \mathrm{y}_{0} \in \mathrm{X}$ such that $\mathrm{g}\left(\mathrm{x}_{0}\right) \preceq \mathrm{F}\left(\mathrm{x}_{0}, \mathrm{y}_{0}\right)$ and $\mathrm{F}\left(\mathrm{y}_{0}, \mathrm{x}_{0}\right) \preceq \mathrm{g}\left(\mathrm{y}_{0}\right)$.

Then $\mathrm{F}$ and $\mathrm{g}$ have a coupled coincidence point if $(*)$ or $(* *)$ holds.

Proof. Consider the sequences $\left\{x_{n}\right\}$ and $\left\{y_{n}\right\}$ with initial points $x_{0}$ and $y_{0}$ constructed in the proof of Theorem 2.1. Let $\mathrm{V} \in \mathcal{V}$ and suppose that $\rho$ is the Minkowski's pseudometric of $\mathrm{V}$. For given comparable elements $(g(x), g(y))$ and $(g(u), g(v))$ of $X \times X$, where $x, y, u, v \in X$, write $r_{1}=\rho(F(x, y), g(x))$ and $r_{2}=\rho(F(u, v), g(u))$ and take $\varepsilon>0$. Then

$$
(F(x, y), g(x)) \in\left(r_{1}+\varepsilon\right) V \text { and }(F(u, v), g(u)) \in\left(r_{2}+\varepsilon\right) V .
$$

Therefore, by (2.6),

$$
(F(x, y), F(u, v)) \in \alpha\left(r_{1}+\varepsilon\right) V \circ \beta\left(r_{2}+\varepsilon\right) V .
$$

By Lemma 1.1, we have

$$
\rho(F(x, y), F(u, v))<\alpha\left(r_{1}+\varepsilon\right)+\beta\left(r_{2}+\varepsilon\right)=\alpha r_{1}+\beta r_{2}+(\alpha+\beta) \varepsilon .
$$

Since $\varepsilon>0$ was arbitrary, it follows that

$$
\rho(F(x, y), F(u, v)) \leq \alpha \rho(F(x, y), g(x))+\beta \rho(F(u, v), g(u)) .
$$


Next, by Lemma 1.1, choose a $\lambda>0$ such that $\left(g\left(x_{1}\right), g\left(x_{0}\right)\right) \in \lambda V$. Because $\left(g\left(x_{n}\right), g\left(y_{n}\right)\right)$ and $\left(g\left(x_{n-1}\right), g\left(y_{n-1}\right)\right)$ are comparable, by $(2.7)$, we have

$$
\begin{aligned}
\rho\left(g\left(x_{n+1}\right), g\left(x_{n}\right)\right) & =\rho\left(F\left(x_{n}, y_{n}\right), F\left(x_{n-1}, y_{n-1}\right)\right) \\
& \leq \alpha \rho\left(F\left(x_{n}, y_{n}\right), g\left(x_{n}\right)\right)+\beta \rho\left(F\left(x_{n-1}, y_{n-1}\right), g\left(x_{n-1}\right)\right) \\
& =\alpha \rho\left(g\left(x_{n+1}\right), g\left(x_{n}\right)\right)+\beta \rho\left(g\left(x_{n}\right), g\left(x_{n-1}\right)\right) .
\end{aligned}
$$

Thus, for each $n \geq 1$, the inequality

$$
\rho\left(g\left(x_{n+1}\right), g\left(x_{n}\right)\right) \leq \delta \rho\left(g\left(x_{n}\right), g\left(x_{n-1}\right)\right)
$$

holds, where $\delta=\frac{\beta}{1-\alpha}$. Clearly, $0<\delta<1$ and, by induction, we have

$$
\rho\left(g\left(x_{n+1}\right), g\left(x_{n}\right)\right) \leq \delta^{n} \rho\left(g\left(x_{1}\right), g\left(x_{0}\right)\right) \quad(n \geq 0) .
$$

Hence, for sufficiently large $m$ and $n$ with $m>n$ we have

$$
\begin{aligned}
\rho\left(g\left(x_{m}\right), g\left(x_{n}\right)\right) & \leq \rho\left(g\left(x_{m}\right), g\left(x_{m-1}\right)\right)+\cdots+\rho\left(g\left(x_{n+1}\right), g\left(x_{n}\right)\right) \\
& \leq \delta^{m-1} \rho\left(g\left(x_{1}\right), g\left(x_{0}\right)\right)+\cdots+\delta^{n} \rho\left(g\left(x_{1}\right), g\left(x_{0}\right)\right) \\
& <\frac{\delta^{n}}{1-\delta} \lambda<1,
\end{aligned}
$$

that is, $\left(g\left(x_{m}\right), g\left(x_{n}\right)\right) \in V$. Therefore, $\left\{g\left(x_{n}\right)\right\}$ is a Cauchy sequence in $g(X)$. Similarly, $\left\{g\left(y_{n}\right)\right\}$ is Cauchy, and so there exist $x, y \in X$ such that $g\left(x_{n}\right) \rightarrow g(x)$ and $g\left(y_{n}\right) \rightarrow g(y)$.

Now, if $(*)$ holds, then an argument similar to that in the proof of Theorem 2.1 establishes that $(\mathrm{g}(\mathrm{x}), \mathrm{g}(\mathrm{y}))$ is a coupled coincidence point if $\mathrm{F}$ and $\mathrm{g}$. If $(* *)$ holds, then

$$
g\left(x_{n}\right) \preceq g(x) \quad \text { and } \quad g(y) \preceq g\left(y_{n}\right),
$$

for all $n \geq 1$. Thus, $(g(x), g(y))$ is comparable to each $\left(g\left(x_{n}\right), g\left(y_{n}\right)\right)$. Now, suppose $V \in \mathcal{V}$ and $\rho$ is the Minkowski's pseudometric of $V$. Then, by (2.7), for each $n \geq 0$ we have

$$
\begin{aligned}
\rho(F(x, y), g(x)) & \leq \rho\left(F(x, y), g\left(x_{n+1}\right)\right)+\rho\left(g\left(x_{n+1}\right), g(x)\right) \\
& =\rho\left(F(x, y), F\left(x_{n}, y_{n}\right)\right)+\rho\left(g\left(x_{n+1}\right), g(x)\right) \\
& \leq \alpha \rho(F(x, y), g(x))+\beta \rho\left(F\left(x_{n}, y_{n}\right), g\left(x_{n}\right)\right)+\rho\left(g\left(x_{n+1}\right), g(x)\right) \\
& =\alpha \rho(F(x, y), g(x))+\beta \rho\left(g\left(x_{n+1}\right), g\left(x_{n}\right)\right)+\rho\left(g\left(x_{n+1}\right), g(x)\right) .
\end{aligned}
$$

Since the Minkowoski's pseudometrics are jointly continuous, hence for sufficiently large $n$ we obtain

$$
\rho(F(x, y), g(x)) \leq \frac{\beta}{1-\alpha} \rho\left(g\left(x_{n+1}\right), g\left(x_{n}\right)\right)+\frac{1}{1-\alpha} \rho\left(g\left(x_{n+1}\right), g(x)\right)<1,
$$

that is, $(F(x, y), g(x)) \in V$. Since $V$ is arbitrary and $X$ is separated, we get $F(x, y)=g(x)$. Similarly, $F(y, x)=g(y)$ and so, $(x, y)$ is a coupled coincidence point for $F$ and $g$. 
We easily get the following consequence of Theorem 2.2 in partially ordered metric spaces:

Corolary 2. Let $(\mathrm{X}, \preceq)$ be a partially ordered set and $\mathrm{d}$ be a metric on $\mathrm{X}$. Suppose that the pair $(\mathrm{F}, \mathrm{g})$ satisfies the following conditions:

i) there exist $\alpha, \beta>0$ with $\alpha+\beta<1$ such that

$$
(F(x, y), F(u, v)) \in \alpha V\left(d, r_{1}\right) \circ \beta V\left(d, r_{2}\right)
$$

if $\mathrm{r}_{1}, \mathrm{r}_{2}>0, \mathrm{~d}(\mathrm{~F}(\mathrm{x}, \mathrm{y}), \mathrm{g}(\mathrm{x}))<\mathrm{r}_{1}, \mathrm{~d}(\mathrm{~F}(\mathrm{u}, v), \mathrm{g}(\mathrm{u}))<\mathrm{r}_{2}$, and the pairs $(\mathrm{g}(\mathrm{x}), \mathrm{g}(\mathrm{y}))$ and $(\mathrm{g}(\mathrm{u}), \mathrm{g}(v))$ are comparable, where $\mathrm{x}, \mathrm{y}, \mathrm{u}, v \in \mathrm{X}$;

ii) there exist $\mathrm{x}_{0}, \mathrm{y}_{0} \in \mathrm{X}$ such that $\mathrm{g}\left(\mathrm{x}_{0}\right) \preceq \mathrm{F}\left(\mathrm{x}_{0}, \mathrm{y}_{0}\right)$ and $\mathrm{F}\left(\mathrm{y}_{0}, \mathrm{x}_{0}\right) \preceq \mathrm{g}\left(\mathrm{y}_{0}\right)$.

Then $\mathrm{F}$ and $\mathrm{g}$ have a coupled coincidence point if $(*)$ or $(* *)$ holds.

Theorem 2.3. Suppose that a pair $(\mathrm{F}, \mathrm{g})$ satisfies the following conditions:

i) there exist positive numbers $\alpha$ and $\beta$ with $\alpha+\beta<1$ such that for all $\mathrm{V}_{1}, \mathrm{~V}_{2} \in \mathcal{V}$, if $(\mathrm{F}(\mathrm{x}, \mathrm{y}), \mathrm{g}(\mathrm{u})) \in$ $\mathrm{V}_{1},(\mathrm{~F}(\mathrm{u}, v), \mathrm{g}(\mathrm{x})) \in \mathrm{V}_{2}$, and $(\mathrm{g}(\mathrm{x}), \mathrm{g}(\mathrm{y}))$ and $(\mathrm{g}(\mathrm{u}), \mathrm{g}(\mathrm{v}))$ are comparable, then

$$
(F(x, y), F(u, v)) \in \alpha V_{1} \circ \beta V_{2}
$$

where $\mathrm{x}, \mathrm{y}, \mathrm{u}, \boldsymbol{v} \in \mathrm{X}$;

ii) there exist $\mathrm{x}_{0}, \mathrm{y}_{0} \in \mathrm{X}$ such that $\mathrm{g}\left(\mathrm{x}_{0}\right) \preceq \mathrm{F}\left(\mathrm{x}_{0}, \mathrm{y}_{0}\right)$ and $\mathrm{F}\left(\mathrm{y}_{0}, \mathrm{x}_{0}\right) \preceq \mathrm{g}\left(\mathrm{y}_{0}\right)$.

Then $\mathrm{F}$ and $\mathrm{g}$ have a coupled coincidence point if $(*)$ or $(* *)$ holds.

Proof. Again, we construct the sequences $\left\{x_{n}\right\}$ and $\left\{y_{n}\right\}$ with initial points $x_{0}$ and $y_{0}$ as in the proof of Theorem 2.1. Since $\alpha+\beta<1$, without loss of generality, we assume that $\alpha<\frac{1}{2}$. Let $V \in \mathcal{V}$ and suppose that $\rho$ is the Minkowski's pseudometric of V. For given comparable elements $(g(x), g(y))$ and $(g(u), g(v))$ of $X \times X$, where $x, y, u, v \in X$, write $r_{1}=\rho(F(x, y), g(u))$ and $r_{2}=\rho(F(u, v), g(x))$ and take $\varepsilon>0$. Then

$$
(F(x, y), g(u)) \in\left(r_{1}+\varepsilon\right) V \quad \text { and }(F(u, v), g(x)) \in\left(r_{2}+\varepsilon\right) V .
$$

Therefore, by (2.8),

$$
(F(x, y), F(u, v)) \in \alpha\left(r_{1}+\varepsilon\right) V \circ \beta\left(r_{2}+\varepsilon\right) V
$$

By Lemma 1.1, we have

$$
\rho(F(x, y), F(u, v))<\alpha\left(r_{1}+\varepsilon\right)+\beta\left(r_{2}+\varepsilon\right)=\alpha r_{1}+\beta r_{2}+(\alpha+\beta) \varepsilon
$$

Since $\varepsilon>0$ was arbitrary, it follows that

$$
\rho(F(x, y), F(u, v)) \leq \alpha \rho(F(x, y), g(u))+\beta \rho(F(u, v), g(x)) .
$$


Now, by Lemma 1.1, let $\lambda>0$ be such that $\left(g\left(x_{1}\right), g\left(x_{0}\right)\right) \in \lambda$ V. Because $\left(g\left(x_{n}\right), g\left(y_{n}\right)\right)$ and $\left(g\left(x_{n-1}\right), g\left(y_{n-1}\right)\right)$ are comparable, by $(2.9)$, we have

$$
\begin{aligned}
\rho\left(g\left(x_{n+1}\right), g\left(x_{n}\right)\right) & =\rho\left(F\left(x_{n}, y_{n}\right), F\left(x_{n-1}, y_{n-1}\right)\right) \\
& \leq \alpha \rho\left(F\left(x_{n}, y_{n}\right), g\left(x_{n-1}\right)\right)+\beta \rho\left(F\left(x_{n-1}, y_{n-1}\right), g\left(x_{n}\right)\right) \\
& \leq \alpha \rho\left(F\left(x_{n}, y_{n}\right), g\left(x_{n}\right)\right)+\alpha \rho\left(g\left(x_{n}\right), g\left(x_{n-1}\right)\right) \\
& =\alpha \rho\left(g\left(x_{n+1}\right), g\left(x_{n}\right)\right)+\alpha \rho\left(g\left(x_{n}\right), g\left(x_{n-1}\right)\right) .
\end{aligned}
$$

Thus, for each $n \geq 1$, the inequality

$$
\rho\left(g\left(x_{n+1}\right), g\left(x_{n}\right)\right) \leq \delta \rho\left(g\left(x_{n}\right), g\left(x_{n-1}\right)\right)
$$

holds, where $\delta=\frac{\alpha}{1-\alpha}$. Since $\alpha<\frac{1}{2}$, hence $0<\delta<1$ and, by induction, we have

$$
\rho\left(g\left(x_{n+1}\right), g\left(x_{n}\right)\right) \leq \delta^{n} \rho\left(g\left(x_{1}\right), g\left(x_{0}\right)\right) \quad(n \geq 0) .
$$

Therefore, for sufficiently large $m$ and $n$ with $m>n$ we have

$$
\begin{aligned}
\rho\left(g\left(x_{m}\right), g\left(x_{n}\right)\right) & \leq \rho\left(g\left(x_{m}\right), g\left(x_{m-1}\right)\right)+\cdots+\rho\left(g\left(x_{n+1}\right), g\left(x_{n}\right)\right) \\
& \leq \delta^{m-1} \rho\left(g\left(x_{1}\right), g\left(x_{0}\right)\right)+\cdots+\delta^{n} \rho\left(g\left(x_{1}\right), g\left(x_{0}\right)\right) \\
& <\frac{\delta^{n}}{1-\delta} \lambda<1,
\end{aligned}
$$

that is, $\left(g\left(x_{m}\right), g\left(x_{n}\right)\right) \in V$. Consequently, $\left\{g\left(x_{n}\right)\right\}$ is a Cauchy sequence in $g(X)$. Similarly, $\left\{g\left(y_{n}\right)\right\}$ is Cauchy, and so there exist $x, y \in X$ such that $g\left(x_{n}\right) \rightarrow g(x)$ and $g\left(y_{n}\right) \rightarrow g(y)$.

If $(*)$ holds, then an argument similar to that in the proof of Theorem 2.1 establishes that $(\mathrm{g}(\mathrm{x}), \mathrm{g}(\mathrm{y}))$ is a coupled coincidence point if $\mathrm{F}$ and $\mathrm{g}$. If $(* *)$ holds, then

$$
g\left(x_{n}\right) \preceq g(x) \quad \text { and } \quad g(y) \preceq g\left(y_{n}\right),
$$

for all $n \geq 0$. Thus, $(g(x), g(y))$ is comparable to each $\left(g\left(x_{n}\right), g\left(y_{n}\right)\right)$. If $V \in \mathcal{V}$ and $\rho$ is the Minkowski's pseudometric of $\mathrm{V}$, then by (2.9), for each $n \geq 1$ we have

$$
\begin{aligned}
\rho(F(x, y), g(x)) & \leq \rho\left(F(x, y), g\left(x_{n+1}\right)\right)+\rho\left(g\left(x_{n+1}\right), g(x)\right) \\
& =\rho\left(F(x, y), F\left(x_{n}, y_{n}\right)\right)+\rho\left(g\left(x_{n+1}\right), g(x)\right) \\
& \leq \alpha \rho\left(F(x, y), g\left(x_{n}\right)\right)+\beta \rho\left(F\left(x_{n}, y_{n}\right), g(x)\right)+\rho\left(g\left(x_{n+1}\right), g(x)\right) \\
& \leq \alpha \rho(F(x, y), g(x))+\alpha \rho\left(g(x), g\left(x_{n}\right)\right)+(\beta+1) \rho\left(g\left(x_{n+1}\right), g(x)\right) .
\end{aligned}
$$

Since the Minkowoski's pseudometrics are jointly continuous, hence for sufficiently large $\mathfrak{n}$ we get

$$
\rho(F(x, y), g(x)) \leq \frac{\alpha}{1-\alpha} \rho\left(g(x), g\left(x_{n}\right)\right)+\frac{\beta+1}{1-\alpha} \rho\left(g\left(x_{n+1}\right), g(x)\right)<1,
$$

that is, $(F(x, y), g(x)) \in V$. Since $V$ is arbitrary and $X$ is separated, we have $F(x, y)=g(x)$. Similarly, $F(y, x)=g(y)$ and so, $(x, y)$ is a coupled coincidence point for $F$ and $g$. 
Corolary 3. Let $(\mathrm{X}, \preceq)$ be a partially ordered set and $\mathrm{d}$ be a metric on $\mathrm{X}$. Suppose that the pair $(\mathrm{F}, \mathrm{g})$ satisfies the following conditions:

i) there exist $\alpha, \beta>0$ with $\alpha+\beta<1$ such that

$$
(F(x, y), F(u, v)) \in \alpha V\left(d, r_{1}\right) \circ \beta V\left(d, r_{2}\right)
$$

if $\mathrm{r}_{1}, \mathrm{r}_{2}>0, \mathrm{~d}(\mathrm{~F}(\mathrm{x}, \mathrm{y}), \mathrm{g}(\mathrm{u}))<\mathrm{r}_{1}, \mathrm{~d}(\mathrm{~F}(\mathrm{u}, v), \mathrm{g}(\mathrm{x}))<\mathrm{r}_{2}$, and the pairs $(\mathrm{g}(\mathrm{x}), \mathrm{g}(\mathrm{y}))$ and $(\mathrm{g}(\mathrm{u}), \mathrm{g}(v))$ are comparable, where $\mathrm{x}, \mathrm{y}, \mathrm{u}, v \in \mathrm{X}$;

ii) there exist $\mathrm{x}_{0}, \mathrm{y}_{0} \in \mathrm{X}$ such that $\mathrm{g}\left(\mathrm{x}_{0}\right) \preceq \mathrm{F}\left(\mathrm{x}_{0}, \mathrm{y}_{0}\right)$ and $\mathrm{F}\left(\mathrm{y}_{0}, \mathrm{x}_{0}\right) \preceq \mathrm{g}\left(\mathrm{y}_{0}\right)$.

Then $\mathrm{F}$ and $\mathrm{g}$ have a coupled coincidence point if $(*)$ or $(* *)$ holds.

Received: December 2013. Revised: April 2014.

\section{References}

[1] S. P. Acharya, Some results on fixed points in uniform spaces, Yokohama Math. J. 22 (1974) 105-116.

[2] B. S. Choudhury, A. Kundu, A coupled coincidence point result in partially ordered metric spaces for compatible mappings, Nonlinear Anal. 73 (2010) 2524-2531.

[3] T. Gnana Bhaskar, V. Lakshmikantham, Fixed point theorems in partially ordered metric spaces and applications, Nonlinear Anal. 65 (2006) 1379-1393.

[4] V. Lakshmikantham, L. Ćirić, Coupled fixed point theorems for nonlinear contractions in partially ordered metric spaces, Nonlinear Anal. 70 (2009) 4341-4349.

[5] H. H. Schaefer, Topological vector spaces, Springer-Verlag, New York-Berlin, 1971.

[6] S. Willard, General topology, Addison-Wesley Publishing Co. Reading, Mass.-London-Don Mills, Ont., 1970. 